\title{
Sonochemical synthesis of $\mathrm{CuO}$ nanostructures and their morphology dependent optical and visible light driven photocatalytic properties
}

Article in Journal of Materials Science Materials in Electronics · October 2016

DOI: $10.1007 /$ s10854-016-5817-2

CITATIONS

0

7 authors, including:

Saravanan R

Solar Energy Research Center Chile

48 PUBLICATIONS 446 CITATIONS

SEE PROFILE

Hector Mansilla

University of Concepción

122 PUBLICATIONS 3,142 CITATIONS

SEE PROFILE
READS

60
Francisco Gracia

University of Chile

47 PUBLICATIONS 706 CITATIONS

SEE PROFILE

Miguel Ángel Gracia Pinilla

Autonomous University of Nuevo León

48 PUBLICATIONS 264 CITATIONS

SEE PROFILE

Some of the authors of this publication are also working on these related projects: 


\title{
Sonochemical synthesis of $\mathrm{CuO}$ nanostructures and their morphology dependent optical and visible light driven photocatalytic properties
}

\author{
Thangaraj Pandiyarajan ${ }^{1} \cdot$ Rajendran Saravanan $^{2} \cdot$ Balasubramanian Karthikeyan $^{3}$ • \\ F. Gracia ${ }^{2}$ - Héctor D. Mansilla ${ }^{4}$ M. A. Gracia-Pinilla ${ }^{5,6}$. \\ Ramalinga Viswanathan Mangalaraja ${ }^{1}$
}

Received: 12 August 2016/ Accepted: 3 October 2016

(c) Springer Science+Business Media New York 2016

\begin{abstract}
A controlled synthesis of $\mathrm{CuO}$ nanostructures with various morphologies were successfully achieved by presence/absence of low frequency $(42 \mathrm{kHz})$ ultrasound with two different methods. The size, shape and morphology of the $\mathrm{CuO}$ nanostructures were tailored by altering the ultrasound, mode of addition and solvent medium. The crystalline structure and molecular vibrational modes of the prepared nanostructures were analysed through X-ray diffraction and FTIR measurement, respectively which confirmed that the nanostructures were phase pure high-quality $\mathrm{CuO}$ with monoclinic crystal structure. The morphological evaluation and elemental composition analysis were done using TEM and EDS attached with SEM, respectively. Furthermore, we demonstrated that the
\end{abstract}

Thangaraj Pandiyarajan

rtpandiyarajan@gmail.com

$\triangle$ Ramalinga Viswanathan Mangalaraja mangal@udec.cl

1 Advanced Ceramics and Nanotechnology Laboratory, Department of Materials Engineering, University of Concepcion, Concepción, Chile

2 Department of Chemical Engineering and Biotechnology, University of Chile, Beauchef 850, Santiago, Chile

3 Department of Physics, National Institute of Technology, Tiruchirappalli 620 015, India

4 Department of Organic Chemistry, Faculty of Chemical Sciences, University of Concepcion, Concepción, Chile

5 Facultad de Ciencias Físico-Matemáticas, Universidad Autónoma de Nuevo León, Av. Universidad, Cd. Universitaria, San Nicolás de los Garza, Nuevo León, Mexico

6 Centro de Investigación en Innovación y Desarrollo en Ingeniería y Tecnología, PIIT, Universidad Autónoma de Nuevo León, 66600 Apodaca, Nuevo León, Mexico prepared $\mathrm{CuO}$ nanostructures could be served as an effective photocatalyst towards the degradation of methyl orange (MO) under visible light irradiation. Among the various nanostructures, the spherical shape $\mathrm{CuO}$ nanostructures were found to have the better catalytic activities towards MO dye degradation. The catalytic degradation performance of $\mathrm{MO}$ in the presence of $\mathrm{CuO}$ nanostructures showed the following order: spherical $<$ nanorod $<$ layered oval $<$ nanoleaf $<$ triangular $<$ shuttles structures. The influence of loading and reusability of catalyst revealed that the efficiency of visible light assisted degradation of MO was effectively enhanced and more than $95 \%$ of degradation was achieved after 3 cycles.

\section{Introduction}

The semiconductor nanostructure materials have been drawn considerable interest in recent years because of their unique properties such as a large surface-to-volume ratio leads to the enhanced physical and chemical properties that are not characteristic of the atoms or of their bulk counterparts [1]. Specifically, oxide nano-semiconductors are an important class of semiconductors, which have applications in various technological fields like opto-electronic industry [2], magnetic storage media [3], solar energy transformation [4], sensors [5] and photocatalysis [6]. Among the oxides semiconductors, $\mathrm{CuO}$ nanomaterial has been attracted much attention because of its novel properties towards the application in various technological industries [7]. Naturally, $\mathrm{CuO}$ is a typical $p$-type semiconductor with the narrow band gap between 1.2 and $1.5 \mathrm{eV}$ [8] which makes this material a key component of high temperature superconductors [9], giant magneto-resistance [10] and photoconductive [11]. 
The controlled synthesis of oxide nano-semiconductors with well-defined morphology at low cost has been attracted much attention since the optoelctronic and catalytic properties are strongly influenced by the size [12] and shape $[13,14]$ which make these oxide nano-semiconductors as a potential candidate for environmental catalytic industries. There are several synthesis routes such as solution based technique [15], hydrothermal [16], microwave [17] and ultrasonics [18] have been developed to prepare well-defined nanostructures with different morphologies. The size, shape and morphology of the $\mathrm{CuO}$ nanostructures are greatly affected by various parameters such as concentration of constituents, temperature and aging time [15, 19, 20].

Recent years, the organic pollutants from the industries are increasing day by day which cause a major source of environmental pollutions. There are several semiconductor nanostructures like $\mathrm{CuO}, \mathrm{Fe}_{2} \mathrm{O}_{3}, \mathrm{ZnO}, \mathrm{ZnS}, \mathrm{CuS}$, $\mathrm{Nb}_{2} \mathrm{O}_{5}$ and $\mathrm{TiO}_{2}$ have been developed for the photocatalytic degradation of various organic pollutants [21-27]. Among these semiconductors, $\mathrm{CuO}$ nanostructure is a potential candidate for the catalytic activities due to its higher surface area and ease tuning of size and shape [28]. Methyl orange (MO) is an important coloured compound being used in dyeing and textile industries, which causes toxic to the human health. Therefore, the removal of organic contaminants from the pollutants is an important challenge for the clean environment. Until now, several researchers have reported the photocatalytic activities of $\mathrm{CuO}$ nanostructure and its composites with different morphologies against various organic contaminants. For instance, Li et al. [29] and Liu et al. [30] have reported the photodegradation of rhodamine-B using different $\mathrm{CuO}$ nanostructures and, Wang et al. [31] have studied the photodegradation of methylene blue dye using $\mathrm{CuO}$ nanostructures. Similarly, the photodegradation of methylene blue (MB) and methylene violet (MV) dyes using $\mathrm{CuO}$ nanostructures with different morphologies has been studied by Meshram et al. [32] and Ejhieh et al. [33]. The photodegradation of methyl orange using $\mathrm{CuO}$ nanostructures with different morphologies is rarely reported. Recently, Sharma et al. [34, 35] have reported the structural and photocatalytic investigations on copper oxide nanoparticles and nanocomposites and Chen et al. [36] and Huang et al. [37] have studied the photocatalytic activities of methyl orange using $\mathrm{CuO}$ micro shuttles and microrods.

Owing the importance of $\mathrm{CuO}$ nanostructures in various environmental photocatalysis, we synthesized $\mathrm{CuO}$ nanostructures using presence/absence of low frequency ultrasound $(42 \mathrm{kHz})$ process and different organic solvents medium that allows the formation of nanostructures with an excellent shape and size control. The visible light driven photocatalytic activities of as-prepared $\mathrm{CuO}$ nanostructures were evaluated against methyl orange dye contaminant. Furthermore, the influence of catalyst loading and photostabilty of catalyst were investigated.

\section{Experimental}

\subsection{Synthesis of $\mathrm{CuO}$ nanostructures}

All chemicals used in the experiment were of high purity reagents purchased from Sigma-Aldrich without further purification. Method 1 The $\mathrm{CuO}$ nanostructures were prepared by adding drop-wise $200 \mathrm{ml}$ of $0.05 \mathrm{M}$ copper (II) nitrate trihydrate $\left(\mathrm{Cu}\left(\mathrm{NO}_{3}\right)_{2} \cdot 3 \mathrm{H}_{2} \mathrm{O}\right)$ dissolved in solvent (double distilled water, ethanol and methanol, separately) into $200 \mathrm{ml}$ of $0.1 \mathrm{M} \mathrm{NaOH}$ dissolved in solvent (double distilled water, ethanol and methanol, separately). These mixtures were irradiated separately under ultrasound $(42 \mathrm{kHz})$, continuously for $2 \mathrm{~h}$ at room temperature. The black coloured dispersion formed was kept at room temperature for $16 \mathrm{~h}$ to get the precipitate. The formed precipitates were collected and washed with distilled water and consequently ethanol to remove the unreacted products. The final products were dried in a hot air oven at $60{ }^{\circ} \mathrm{C}$ for $8 \mathrm{~h}$. The samples were code named as $\mathrm{CuO} / \mathrm{UW} /$ $\mathrm{Na}, \mathrm{CuO} / \mathrm{UE} / \mathrm{Na}$ and $\mathrm{CuO} / \mathrm{UM} / \mathrm{Na}$ for distilled water, ethanol and methanol, respectively. The similar procedure was repeated without ultrasonic treatment using double distilled water as solvent and the corresponding sample code is $\mathrm{CuO} / \mathrm{SG} / \mathrm{Na}$.

Method 2 The $\mathrm{CuO}$ nanostructures were prepared by adding drop-wise $200 \mathrm{ml}$ of $0.1 \mathrm{M} \mathrm{NaOH}$ dissolved in double distilled water into $200 \mathrm{ml}$ of $0.05 \mathrm{M}$ copper (II) nitrate trihydrate $\left(\mathrm{Cu}\left(\mathrm{NO}_{3}\right)_{2} \cdot 3 \mathrm{H}_{2} \mathrm{O}\right)$ dissolved in double distilled water. These mixtures were irradiated under ultrasound $(42 \mathrm{kHz})$ continuously for $2 \mathrm{~h}$ at room temperature. Similar procedure was repeated without ultrasonic treatment using double distilled water as solvent. The black coloured dispersion formed was kept at room temperature for $16 \mathrm{~h}$ to get the precipitate. The final product was collected and dried in a hot air oven at $60{ }^{\circ} \mathrm{C}$ for $8 \mathrm{~h}$. The samples were code named as $\mathrm{CuO} / \mathrm{UW}$ and $\mathrm{CuO} / \mathrm{SG}$ for with and without ultrasonic treatment, respectively. The details of samples and their corresponding constituents are presented in Table 1.

\subsection{Characterizations}

The identification of crystallographic phase and the purity of the obtained $\mathrm{CuO}$ nanostructures were carried out by $\mathrm{X}$-ray diffraction (XRD) technique (Bruker, D4 Endeavor). 
Table 1 Sample codes with corresponding experimental condition, morphology, crystallite size and rate constant values

\begin{tabular}{|c|c|c|c|c|c|c|c|}
\hline $\begin{array}{l}\text { Sample } \\
\text { code }\end{array}$ & Parent solution & Addition & Solvent & $\begin{array}{l}\text { Ultrasound } \\
(42 \mathrm{kHz})\end{array}$ & Morphology & $\begin{array}{l}\text { Crystallite size } \\
(\mathrm{nm})\end{array}$ & $\begin{array}{l}\text { Rate constant }(k) 10^{-5} \\
\min ^{-1}\end{array}$ \\
\hline $\begin{array}{l}\mathrm{CuO} / \mathrm{UW} / \\
\mathrm{Na}\end{array}$ & $\mathrm{NaOH}$ & $\mathrm{Cu}\left(\mathrm{NO}_{3}\right)_{2} \cdot 3 \mathrm{H}_{2} \mathrm{O}$ & Water & $2 \mathrm{~h}$ & Nanorods & 11.3 & 4.080 \\
\hline $\begin{array}{l}\mathrm{CuO} / \mathrm{UE} / \\
\mathrm{Na}\end{array}$ & $\mathrm{NaOH}$ & $\mathrm{Cu}\left(\mathrm{NO}_{3}\right)_{2} \cdot 3 \mathrm{H}_{2} \mathrm{O}$ & Ethanol & $2 \mathrm{~h}$ & Spherical & 4.4 & 10.85 \\
\hline $\begin{array}{l}\mathrm{CuO} / \mathrm{UM} / \\
\mathrm{Na}\end{array}$ & $\mathrm{NaOH}$ & $\mathrm{Cu}\left(\mathrm{NO}_{3}\right)_{2} \cdot 3 \mathrm{H}_{2} \mathrm{O}$ & Methanol & $2 \mathrm{~h}$ & Triangular & 3.7 & 1.950 \\
\hline $\begin{array}{l}\mathrm{CuO} / \mathrm{SG} / \\
\mathrm{Na}\end{array}$ & $\mathrm{NaOH}$ & $\mathrm{Cu}\left(\mathrm{NO}_{3}\right)_{2} \cdot 3 \mathrm{H}_{2} \mathrm{O}$ & Water & - & $\begin{array}{l}\text { Layered } \\
\text { oval }\end{array}$ & 12.1 & 3.300 \\
\hline $\mathrm{CuO} / \mathrm{UW}$ & $\mathrm{Cu}\left(\mathrm{NO}_{3}\right)_{2} \cdot 3 \mathrm{H}_{2} \mathrm{O}$ & $\mathrm{NaOH}$ & Water & $2 \mathrm{~h}$ & Nanoleaf & 12.5 & 2.111 \\
\hline $\mathrm{CuO} / \mathrm{SG}$ & $\mathrm{Cu}\left(\mathrm{NO}_{3}\right)_{2} \cdot 3 \mathrm{H}_{2} \mathrm{O}$ & $\mathrm{NaOH}$ & Water & _ & Shuttles & 12.7 & 1.640 \\
\hline
\end{tabular}

The power of the XRD ( $C u-K_{\alpha}$ radiation) was fixed at $40 \mathrm{kV}$ and $30 \mathrm{~mA}$. The measurements were made with $\mathrm{XRD}$ diffraction angle $(2 \theta)$ in the range of $20^{\circ}-80^{\circ}$. The size, shape and morphology of the prepared particles were characterized by transmission electron microscope (TEM, JEOL Model JSM - 6390LV) and scanning electron microscope (SEM, Philips XL30). The elemental composition was identified through energy dispersive spectrometer (EDS) attached with SEM instrument. The optical absorption property was studied by using UV-visible-NIR spectroscopy and was recorded by using Shimadzu dual beam spectrometer in the range of 200-900 nm. The Fourier transform infrared spectroscopy (FTIR) absorption measurements were carried out using Perkin Elmer spectrometer by $\mathrm{KBr}$ pellet technique in the range of $700-400 \mathrm{~cm}^{-1}$.

\subsection{Evaluation of photocatalytic activity}

The evaluation of photocatalytic activities of the prepared $\mathrm{CuO}$ nanostructures was demonstrated by monitoring degradation of MO dye in an aqueous solution in the presence of visible light (Halogen lamp, 7748XHP, $250 \mathrm{~W}$, $24 \mathrm{~V}$ ) and the power density of light irradiation at the surface sample was $180 \pm 20 \mathrm{~mW} / \mathrm{cm}^{2}$. In a typical experiment, the $5 \times 10^{-5} \mathrm{~mol} / \mathrm{l}$ of methyl orange was prepared and $50 \mathrm{mg}$ of synthesized nanocatalyst was added to the dye solution, and then stirred for $30 \mathrm{~min}$ in dark condition to achieve equilibrium. During the catalytic experiments, the nanocatalysts were separated from the suspension by using a $0.21 \mu \mathrm{m}$ polytetrafluoroethylene (PTFE) filter in the regular intervals $(30 \mathrm{~min})$ of time. The degradation of MO was determined by measuring the absorption at $\lambda_{\max }=464 \mathrm{~nm}$ using UV-Vis spectrophotometer (Perkin Elmer Lambda 11).

\section{Results and discussion}

\subsection{Structural characterization}

The crystalline structure and phase purity of the as-prepared $\mathrm{CuO}$ nanostructures were characterized by XRD. Figure 1 shows the XRD patterns of $\mathrm{CuO}$ nanostructures obtained by various experimental conditions. All the diffraction peaks can be indexed as monoclinic $\mathrm{CuO}$ phase and match well with the joint committee on powder diffraction standards (JCPDS No. 801916) data. The major diffraction peaks located at the $2 \theta$ angles of $35.48^{\circ}$ and $38.66^{\circ}$ can be readily indexed as $(-111)$ and (111), respectively. Similarly, other peaks found at the angles of

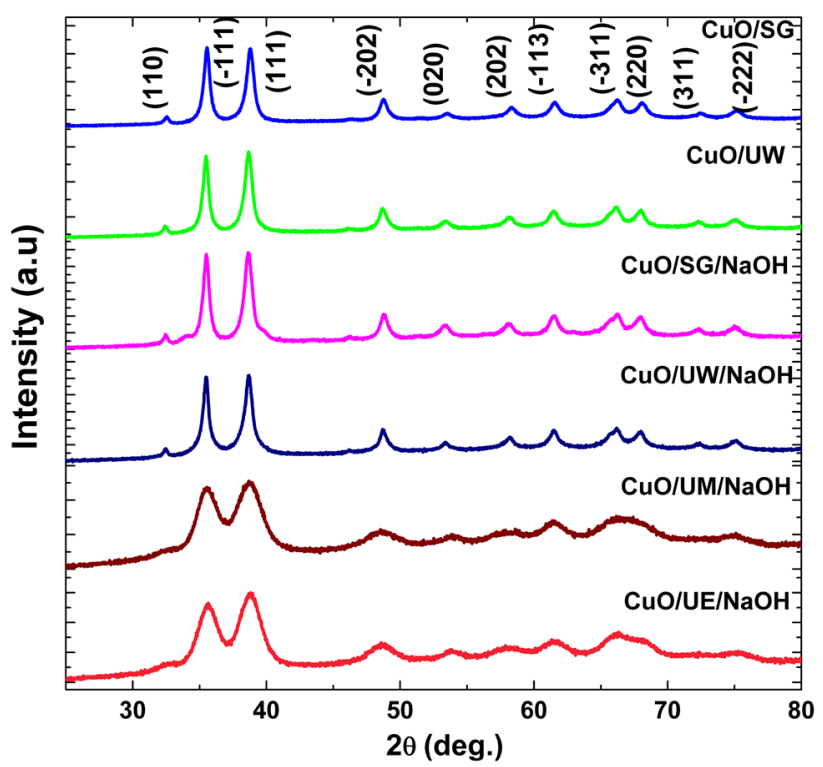

Fig. 1 XRD patterns of the prepared $\mathrm{CuO}$ nanostructures 
$32.38^{\circ}, 46.01^{\circ}, 48.69^{\circ}, 53.44^{\circ}, 58.14^{\circ}, 61.51^{\circ}, 66.13^{\circ}$, $68.02^{\circ}, 72.28^{\circ}$, and $75.02^{\circ}$ are assigned to the planes of (110), (-112), (-202), (020), (202), (-113), (-311), (220), (311) and (-222), respectively. There are no characteristic peaks of impurities, like $\mathrm{Cu}(\mathrm{OH})_{2}$ or $\mathrm{Cu}_{2} \mathrm{O}$, which indicating that the prepared $\mathrm{CuO}$ nanostructures are phase pure. In addition, broadening of full-width at half maximum (FWHM) was observed with respect to the size and shape of the nanostructures and the crystallite size was estimated using Debye-Scherer formula [38], and the obtained values are displayed in Table 1 . The crystallite sizes are found to decrease in the order of water $<$ ethanol $<$ methanol, used as a solvents. It clearly revealed that the solvent medium can significantly control the crystallite size and it can be explained by comparing the dielectric constants $(\varepsilon)$ of water, ethanol and methanol which are 80,21, and 25, respectively at $20{ }^{\circ} \mathrm{C}$. As an example, Ayyappan et al. [39] demonstrated the increase of crystallite size with respect to the dielectric constant values. In the present case, it seems that the dielectric constant of solvent medium significantly affected the crystallite size of the $\mathrm{CuO}$ nanostructures.

\subsection{Morphological studies}

The size, shape and morphology of the $\mathrm{CuO}$ nanostructures prepared with different synthetic conditions were characterized by TEM. Figures 2 and 3 show typical TEM images of $\mathrm{CuO}$ nanostructures synthesized using different conditions and the images clearly revealed that the solvents and ultrasound has effectively influenced on the morphology and size of $\mathrm{CuO}$ nanostructures. The TEM images indicated that the $\mathrm{CuO}$ nanostructures prepared using without ultrasound shows the shuttle (with an average breadth of $220 \mathrm{~nm}$ and length of $708 \mathrm{~nm}$ ) and layered oval like morphologies for $\mathrm{CuO} / \mathrm{SG}$ and $\mathrm{CuO} / \mathrm{SG} /$ $\mathrm{Na}$, respectively. On the other hand, with ultrasound, the particles prepared using water as a solvent reflects nanoleaf like morphology $(\mathrm{CuO} / \mathrm{UW})$ and nanorods $(\mathrm{CuO} / \mathrm{UW} /$ $\mathrm{Na}$ ). Similarly, the particles prepared using ethanol as a solvent exhibits spherical (average particle size $\sim 14 \mathrm{~nm}$ ) like nature, whereas methanol leads to the triangular shape particles.

Morphology and elemental composition of the prepared nanostructures were analysed through EDS attached with SEM instrument. Figure 4 shows the SEM and EDS spectra of $\mathrm{CuO}$ nanostructures $(\mathrm{CuO} / \mathrm{SG}$ and $\mathrm{CuO} / \mathrm{SG} / \mathrm{Na})$ synthesized without ultrasound. The SEM images revealed that the materials are oval shape and flakes like structure. From EDS measurements, it can be seen that $\mathrm{Cu}$ peaks are located at $0.93,8.05$, and $8.91 \mathrm{keV}$ and oxygen peak at about $0.52 \mathrm{keV}$ without other impurities peak which confirm that the prepared nanostructures are pure $\mathrm{CuO}$. These results are consistent with the XRD pattern. The schematic representation of the formation of various shapes of $\mathrm{CuO}$
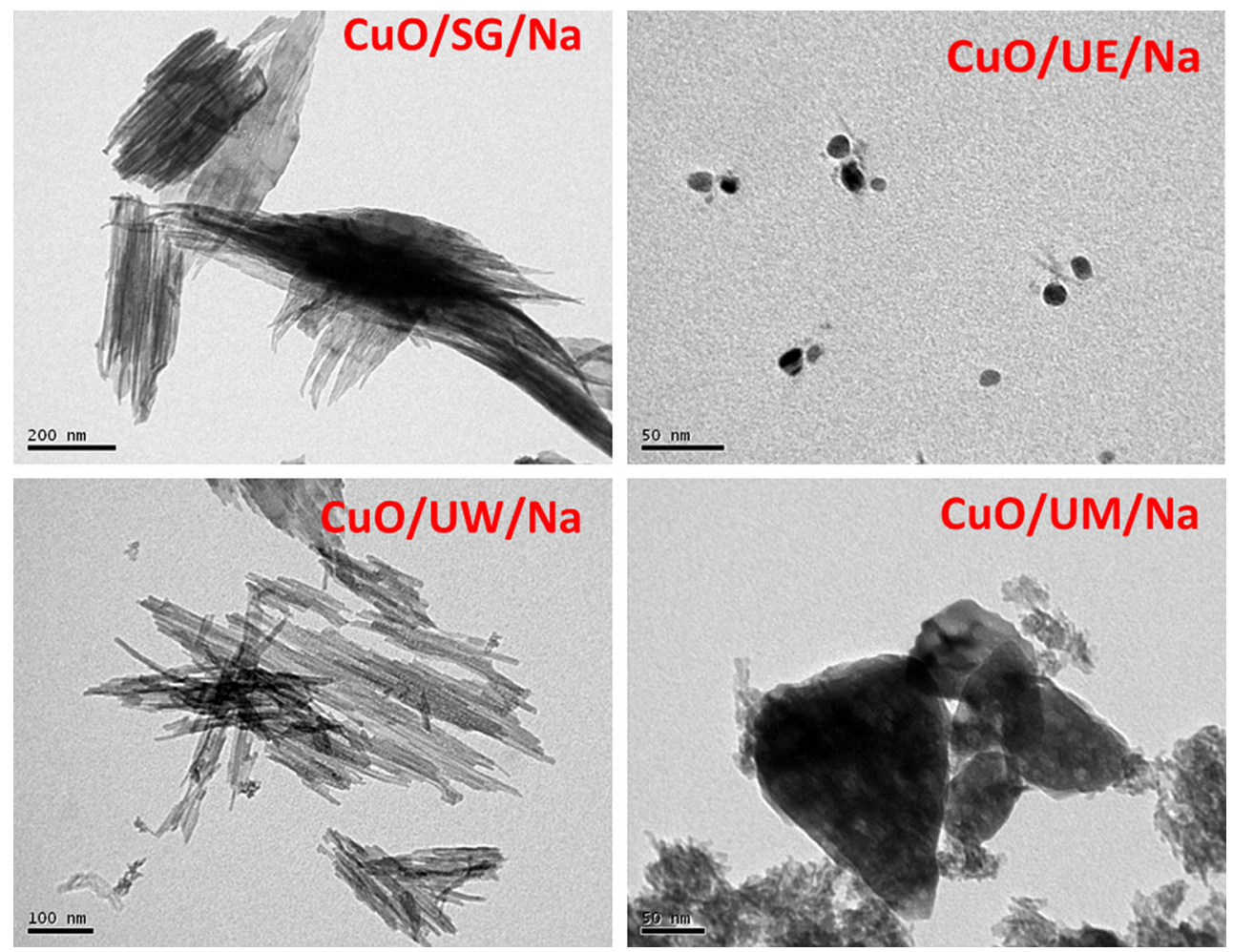

Fig. 2 TEM images of $\mathrm{CuO}$ nanostructures synthesized by the addition of copper precursors into $\mathrm{NaOH}$ solution 

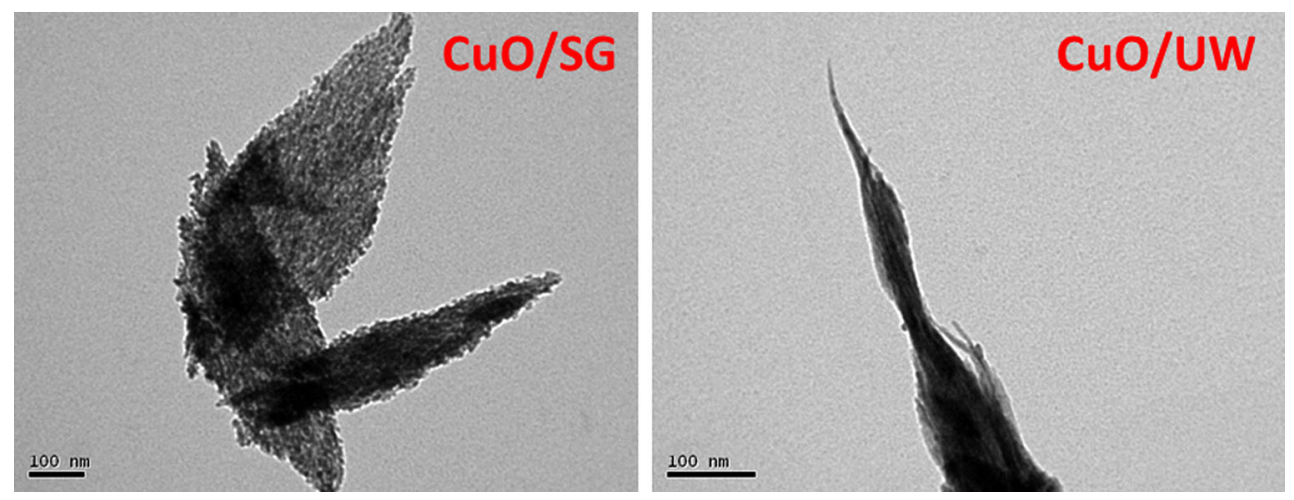

Fig. 3 TEM images of $\mathrm{CuO}$ nanostructures synthesized by the addition of $\mathrm{NaOH}$ into copper precursors

Fig. 4 SEM and EDS spectra of $\mathrm{CuO}$ nanostructures synthesized without ultrasound
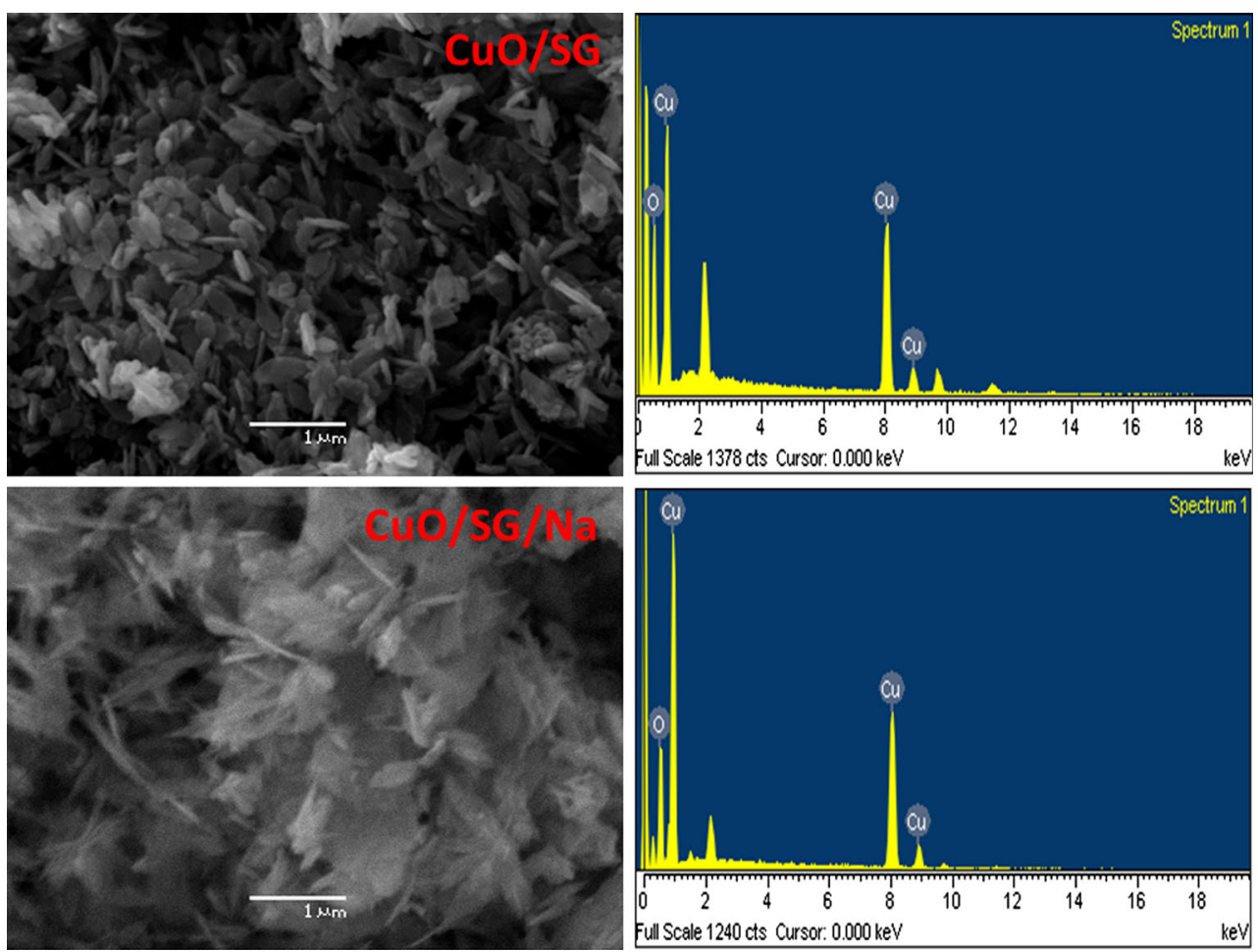

nanostructures under different synthesis routes is shown in Fig. 5.

\subsection{Absorption}

The optical properties of nanostructures are strongly depending on the size and shape of the nanostructures [20]. The shape dependent optical absorption spectra of $\mathrm{CuO}$ nanostructures are shown in Fig. 6. UV spectra of the all samples clearly exhibited two bands appeared at around 285 and $363 \mathrm{~nm}$. Previous reports revealed that the shape and size of $\mathrm{CuO}$ nanostructures greatly influenced on the optical properties. The affecting the status of polarization such as the modification on the distribution of dipole and the electric field could induced the absorption cross section response as the shape and size changes (extrinsic properties) and the modification in the energy band structures (intrinsic properties) [40]. The anomalous absorption band located at $280 \mathrm{~nm}$ is rarely found in the literature [20] and this peak is suggested to be an absorption cross section that is affected by the distribution of dipole or electric field of the sample. Meanwhile, the positions of the absorption band get shifted towards the higher wavelength due to the increase of particle dimension.

\subsection{FTIR}

To investigate the local structure and phonon properties of the prepared nanostructures, Fourier transform infrared spectroscopy analysis in the region of $700-400 \mathrm{~cm}^{-1}$ was 

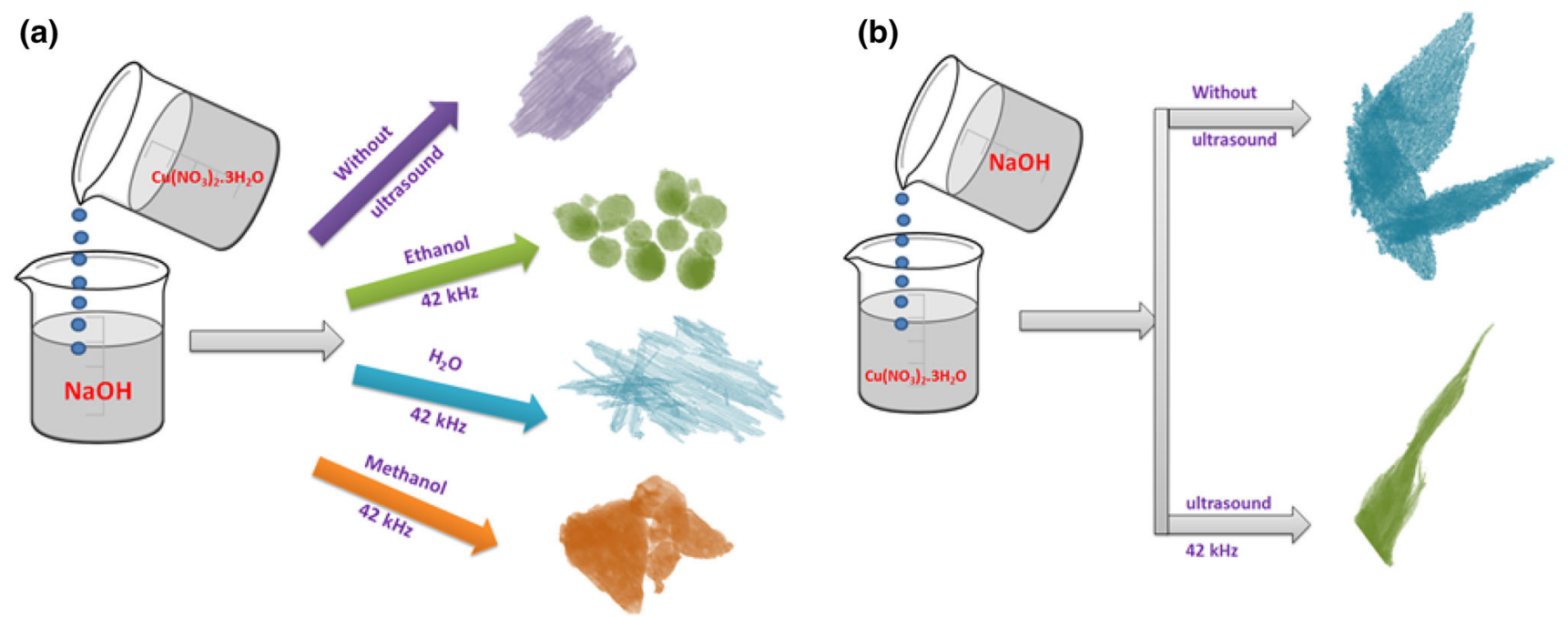

Fig. 5 Pictorial representation of the formation of different shapes of $\mathrm{CuO}$ nanostructures by the synthesis routes a method 1 , $\mathbf{b}$ method 2

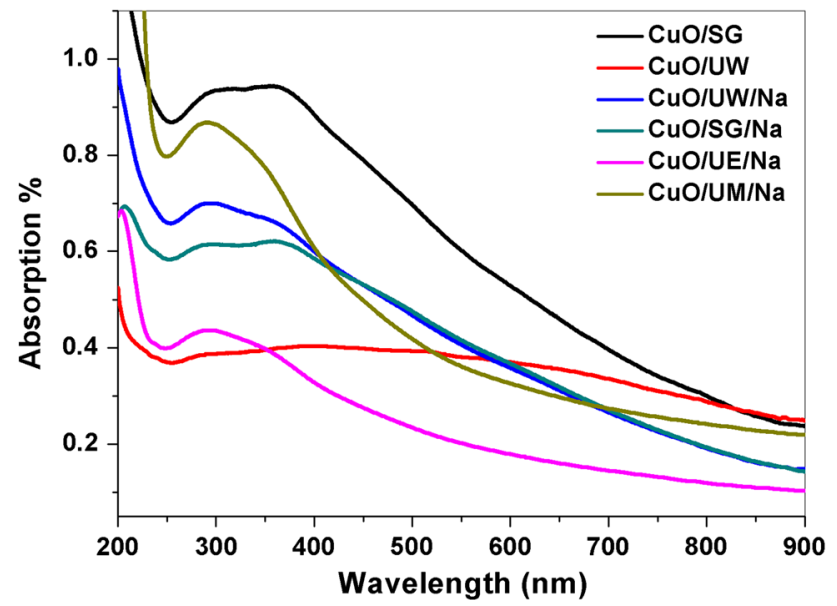

Fig. 6 Optical absorption spectra of $\mathrm{CuO}$ nanostructures synthesized by different experimental conditions

done. Naturally, $\mathrm{CuO}$ is a monoclinic crystal structure with the space group of $\mathrm{C}_{2 \mathrm{~h}}^{6}\left(\mathrm{C}_{/ \mathrm{c}}\right)$ and it has 12 phonon branches due to the 4 atoms in the primitive cell.

Factor group analysis predicts that the vibrational modes are at zone centre [41].

$$
\begin{aligned}
& C u\left(C_{i}\right): \Gamma=3 A_{u}+3 B_{u}, \\
& O\left(C_{2}\right): \Gamma=A_{u}+2 B_{g}+A_{u}+2 B_{u}, \\
& \Gamma^{\text {Total }}=A_{g}+2 B_{g}+4 A_{u}+5 B_{u}
\end{aligned}
$$

The $1 A_{u}\left(T_{y}\right)$ and $2 B_{u}\left(T_{x}, T_{z}\right)$ are acoustical phonon branches, so that the total vibrational modes at $(q=0)$ are $\Gamma^{\text {Total }}=A_{g}+2 B_{g}+3 A_{u}+3 B_{u}$. Where, $A_{g}$ and $B_{g}$ are Raman active modes and $A_{u}$ and $B_{u}$ are infrared active modes. Mid infrared spectra of the prepared $\mathrm{CuO}$ nanostructures in the region of $400-700 \mathrm{~cm}^{-1}$ are displayed in Fig. 7. The characteristic vibrational bands of $\mathrm{CuO}$ are located at 419 for $A_{u}$ and 511 and $607 \mathrm{~cm}^{-1}$ for $B_{u}$ modes [42]. The vibrational band appeared in the higher frequency region at $607 \mathrm{~cm}^{-1}$ is assigned to the $\mathrm{Cu}-\mathrm{O}$ stretching vibrations along [-101] direction and similarly, the band located at $511 \mathrm{~cm}^{-1}$ could be assigned to the vibrations along [101] direction [8] (Table 2). Moreover, all the vibrational frequencies are changed with respect to the observed morphology of the particles. These variations are attributed due to the size- and shape-induced lattice variations as well as the crystal defects like surface unsaturated coordination sites [43, 44].

\section{Photocatalysis study}

\subsection{Effect of photocatalyst}

The photo-degradation activities of the prepared $\mathrm{CuO}$ nanostructures with different morphology were determined by monitoring the degradation of $\mathrm{MO}$ dye. The characteristic absorption band of MO dye at $460 \mathrm{~nm}$ was gradually decreased as a function of visible light irradiation time. Figure 8 represents the degradation performance $\mathrm{CuO}$ nanostructures with different morphologies on $\mathrm{MO}$ dyes. From the graph, it can be seen that the $\mathrm{CuO} / \mathrm{UE} / \mathrm{Na}$ nanostructures exhibited higher catalytic activities and $\mathrm{CuO} / \mathrm{SG}$ nanostructures showed lowest catalytic activities in $180 \mathrm{~min}$. The sequence of percentage of degradation performance is as follows: $95.7,81.5,71.9,51.8,50.4$ and $44.9 \%$ for $\mathrm{CuO} / \mathrm{UE} / \mathrm{Na}, \mathrm{CuO} / \mathrm{UW} / \mathrm{Na}, \mathrm{CuO} / \mathrm{SG} / \mathrm{Na}, \mathrm{CuO} /$ $\mathrm{UW}, \mathrm{CuO} / \mathrm{UM} / \mathrm{Na}$ and $\mathrm{CuO} / \mathrm{SG}$, respectively. The photocatalytic performances of $\mathrm{CuO}$ with respect to the various shapes and pollutants are presented in Table 3. The degradation of organic pollutants in photocatalytic process 

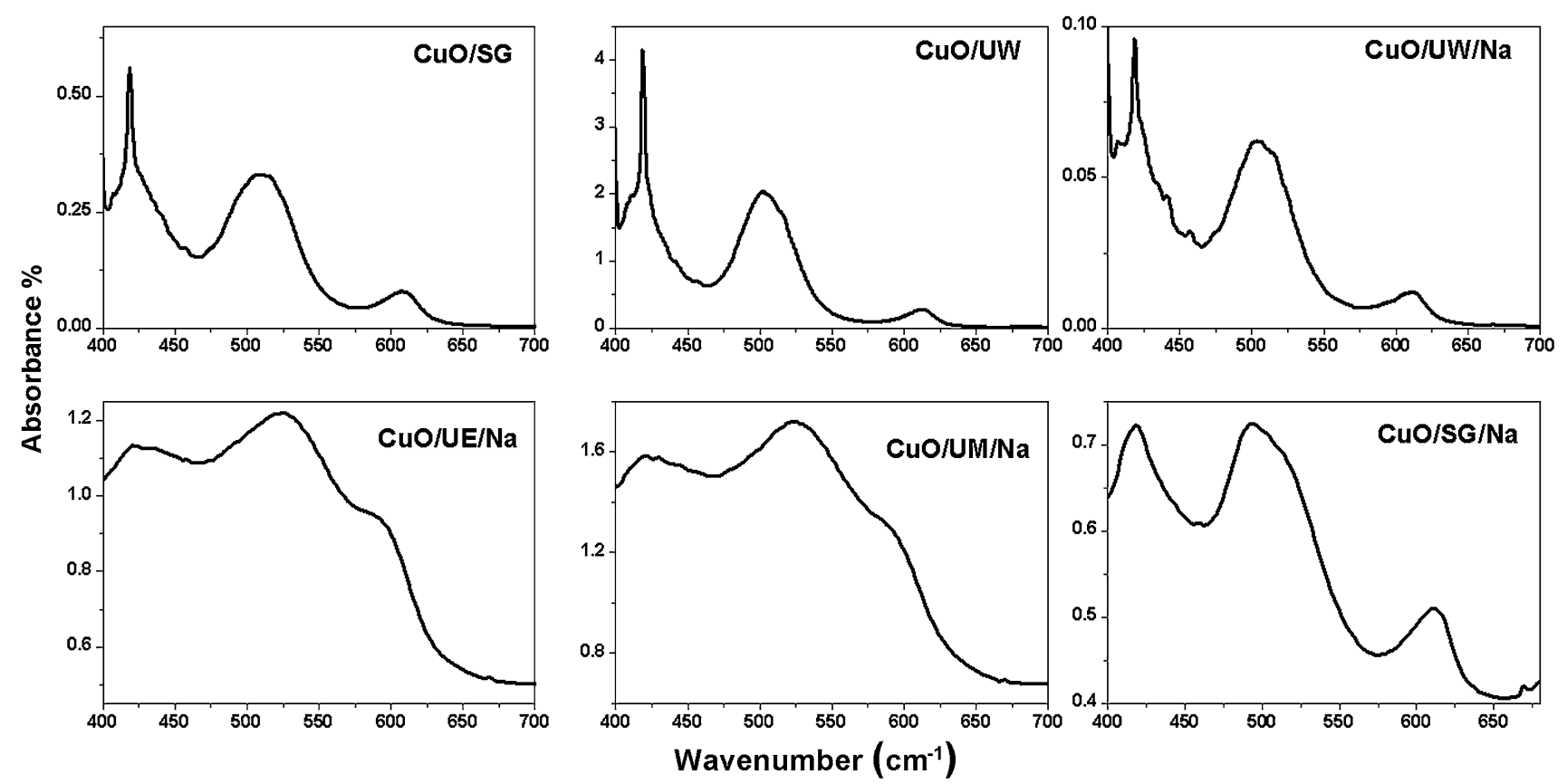

Fig. $7 \mathrm{Mid}$ infrared absorbance spectra of $\mathrm{CuO}$ nanostructures prepared by using different experimental conditions

Table 2 Infrared vibrational frequency and corresponding mode assignments

\begin{tabular}{lllllll}
\hline \multicolumn{2}{l}{ Vibrational frequency $\left(\mathrm{cm}^{-1}\right)$} & & \multicolumn{3}{c}{ Mode assignment } \\
\cline { 1 - 5 } $\mathrm{CuO} / \mathrm{SG} / \mathrm{Na}$ & $\mathrm{CuO} / \mathrm{UW} / \mathrm{Na}$ & $\mathrm{CuO} / \mathrm{UE} / \mathrm{Na}$ & $\mathrm{CuO} / \mathrm{UM} / \mathrm{Na}$ & $\mathrm{CuO} / \mathrm{SG}$ & $\mathrm{CuO} / \mathrm{UW}$ & \\
\hline 609 & 612 & 590 & 591 & 607 & 614 & $B_{u}$ \\
492 & 504 & 518 & 520 & 511 & 502 & $B_{u}$ \\
418 & 419 & 420 & 418 & 419 & 419 & $A_{u}$ \\
\hline
\end{tabular}

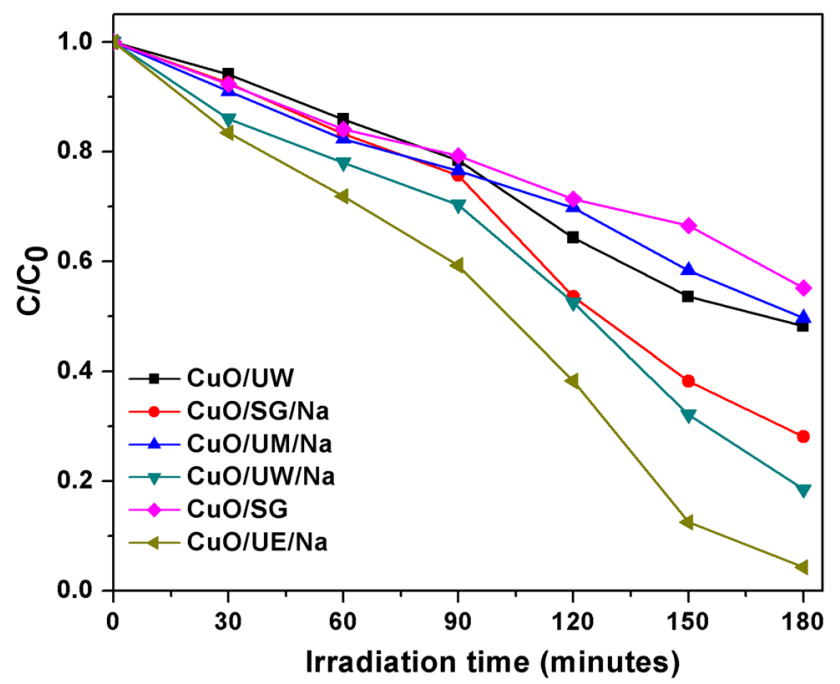

Fig. 8 Photo-degradation of $\mathrm{MO}$ using $\mathrm{CuO}$ nanostructures with different morphologies

undergoes several stages which are as follows: Initially the organic pollutant will be adsorbed on the surface of catalyst. Secondly, when the light energy feed into the system, the electrons $\left(\mathrm{e}_{\mathrm{cb}}^{-}\right)$in the valence band are excited into conduction band leaving behind the holes $\left(\mathrm{h}_{\mathrm{vb}}^{+}\right)$in the valence band and, the photo generated electrons are scavenged by molecular oxygen to produce superoxide radical anions $\left(\mathrm{O}_{2}{ }^{-}\right)$and hydrogen peroxide $\left(\mathrm{H}_{2} \mathrm{O}_{2}\right)$ [34]. The overall photocatalytic reactions are as follows [34, 46]:

$\mathrm{CuO}+h v($ light $) \rightarrow \mathrm{CuO}\left(e_{c b}^{-}+h_{v b}^{+}\right)$

$\mathrm{O}_{2}+e^{-} \rightarrow \mathrm{O}_{2}^{-}$

$2 \mathrm{H}^{+}+\mathrm{O}_{2}+2 e^{-} \rightarrow \mathrm{H}_{2} \mathrm{O}_{2}$

The created holes and the intermediate products are responsible for the production of hydroxyl radicals $\left[\left(\mathrm{OH}^{-}\right)\right.$ and $(\mathrm{OH})]$ in the solutions

$\mathrm{H}_{2} \mathrm{O}+h^{+} \rightarrow \mathrm{OH}+\mathrm{H}^{+}$
$\mathrm{O}_{2}^{-}+\mathrm{H}_{2} \mathrm{O} \rightarrow \mathrm{O}_{2}+\mathrm{OH}^{-}+\mathrm{OH}$

The $\mathrm{OH}$ radicals are the main source of oxidizing agent to degrade the organic pollutants and the reactive oxygen species and holes participated to the oxidative pathways in the degradation of pollutants which are represented as follows [34, 45]: 
Table 3 The photocatalytic performances of $\mathrm{CuO}$ with respect to the various shapes and pollutants

\begin{tabular}{|c|c|c|c|c|}
\hline Catalyst & Morphology & Pollutant & Removal of the efficiency (percentage of degradation activity) & References \\
\hline $\mathrm{CuO}$ & Nanorods & $\mathrm{CH}_{3} \mathrm{CN}$ & $99 \%$ & {$[51]$} \\
\hline $\mathrm{CuO}: \mathrm{Au}$ & Flakes & $\begin{array}{l}\text { Rhodamine B } \\
\text { (RB) }\end{array}$ & $49.40 \%$ for $\mathrm{CuO}$ flakes and $83.90 \%$ for $\mathrm{CuO}: \mathrm{Au}$ & {$[52]$} \\
\hline CuO:rGO & Quantum dots & Methylene blue & $99 \%$ & {$[53]$} \\
\hline $\mathrm{CuO} /$ Zeolite & Spherical & Methyl orange & $90 \%$ & {$[54]$} \\
\hline $\mathrm{C}-\mathrm{CuO}$ & Nanoribbons & Methyl orange & $96.64 \%$ & {$[55]$} \\
\hline GO-CuO-PTh & Spherical & Methylene blue & $83.15 \%$ & {$[56]$} \\
\hline $\begin{array}{l}\text { Metal } \\
\text { oxide@CuO }\end{array}$ & Hierarchical & Congo red dye & $\begin{array}{l}94,90 \% \text { for } \mathrm{Fe}_{2} \mathrm{O}_{3}: \mathrm{CuO} \text { and } \mathrm{ZnO}: \mathrm{CuO} \text {, respectively under solar } \\
\text { radiation }\end{array}$ & [57] \\
\hline $\mathrm{CuO}$ & $\begin{array}{l}\text { Ultralong } \\
\text { nanowires }\end{array}$ & $\begin{array}{l}\text { Rhodamine B } \\
\text { (RB) }\end{array}$ & $97.2 \%$ & {$[58]$} \\
\hline
\end{tabular}

$\mathrm{MB}+\mathrm{O}_{2}^{-} \rightarrow \mathrm{CO}_{2}+\mathrm{H}_{2} \mathrm{O}$

$\mathrm{MB}+h^{+} \rightarrow \mathrm{CO}_{2}+\mathrm{H}_{2} \mathrm{O}$

The nanostructures of smaller in size possess a higher surface area which leads to the extensive adsorption reactions of the contaminants [45]. In addition to that smaller nanostructured materials possess higher migration rates of photo-generated charge carriers towards the surface [35]. In the present studies, the TEM results confirmed that the spherical particles are in the range of $10-15 \mathrm{~nm}$. The similar kind of observation has been reported by Sharma et al. [34].

The photocatalytic degradation of MO under visible light irradiation obeyed pseudo-first order kinetics is expressed by the following equation [47].

$\mathrm{k}=\ln \left(C / C_{0}\right) / t$

where, $C_{O}$ and $\mathrm{C}$ are the concentrations of model dyes at the irradiation time 0 and $t$ minutes, respectively. The calculated apparent rate constant $(k)$ values are listed in Table 1. The values clearly indicated that the spherical nanostructures have high reaction rate than the other morphologies due to their smaller size in the range of 10-15 nm (Fig. 2). It is well known that when the particle size decreases, the surface area increases. The higher surface area of the photocatalyst significantly improves the redox reaction during the visible light irradiation and the surface properties led to influence the efficiency of catalyst [48]. Furthermore, the morphology of the photocatalyst also played a vital role to influence the final degradation efficiency as reported earlier [42, 49]. The similar observation was reported by Saravanan et al., where, the spherical shaped nano zinc oxide exposed superior photocatalytic activity when compared with the spindle and rod shaped zinc oxide nanostructures [50].

\subsection{Effect of catalyst concentration}

The amount of catalyst is one of the important factors for affecting the degradation of dyes and also to avoid the excess usage of catalyst in the experiments. The influence of catalyst loading of $\mathrm{CuO} / \mathrm{UE} / \mathrm{Na}$ on degradation of $\mathrm{MO}$ is displayed in Fig. 9a. The percentage of MO degradation was found to be 53.57, 60.8, 69.7, 85.7 and $95.7 \%$ for 10 , $20,30,40$ and $50 \mathrm{mg} / \mathrm{l}$, respectively, and the percentage of MO degradation was increased with respect to the amount of catalyst. There are different parameters are responsible for the enhanced percentage of degradation rate upon loading of $\mathrm{CuO}$ catalyst. When the concentration of catalyst is more, the photoactive site is increased through light scattering and reflection and also the surface active sites are increased considerably [59]. Similarly, the absorption of photon rate is increased with respect to the catalyst concentrations [60]. All these features are responsible for the increase in photo-induced charge carriers at the catalyst surface which leads to increase the $\mathrm{OH}$ radicals, thus result in an enhanced visible light photodegradation of MO.

\subsection{Reusability studies}

Reusability study is an important parameter to analysis the photostabilty and photocorrosion properties of the catalyst for industrial applications [61]. This is because of the photostabilty may diminished upon direct illumination of visible light. Figure 9a represents the reusability study of $\mathrm{CuO} / \mathrm{UE} / \mathrm{Na}$ spherical nanostructures catalyst for degradation of MO for three subsequent cycles. To study the photostability of catalyst, we collected the catalyst remained after the degradation reaction, washed and dried at $100{ }^{\circ} \mathrm{C}$ for $15 \mathrm{~min}$, and it was used for further reactions. The catalyst was found to be active for 3 cycles 

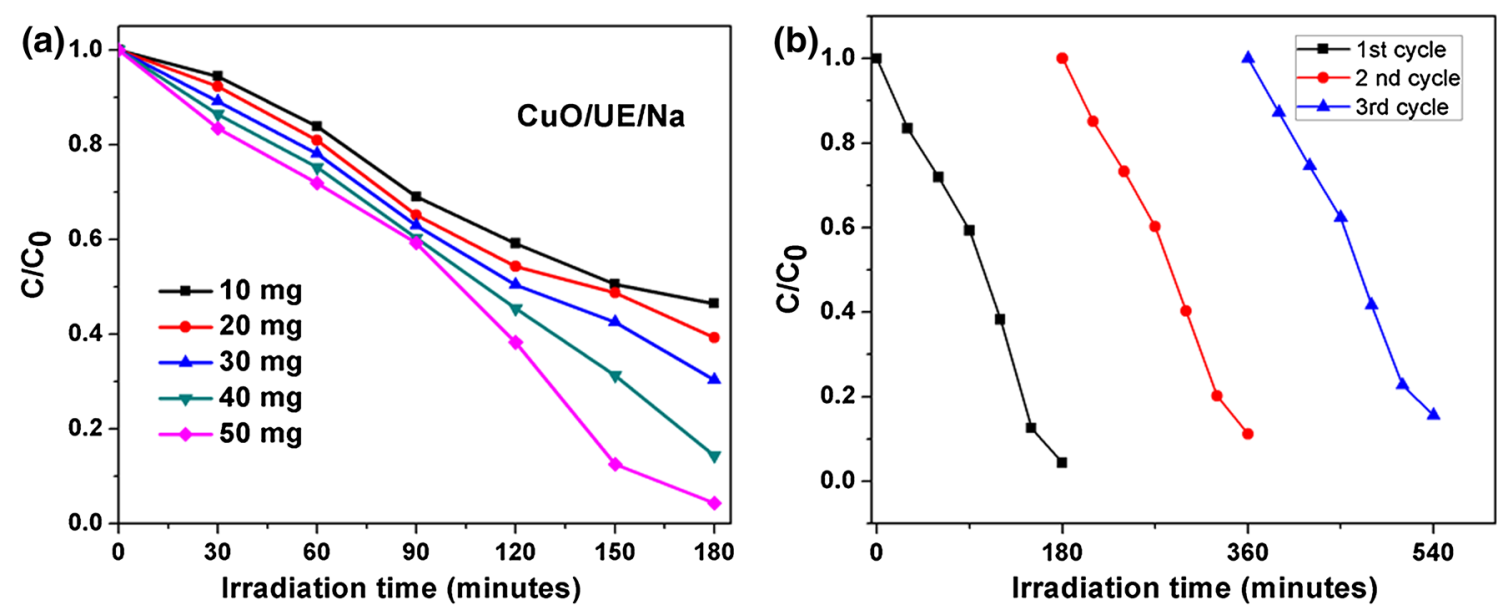

Fig. 9 a Effect of catalyst concentration $(10,20,30,40$ and $50 \mathrm{mg} / \mathrm{l}$ of $\mathrm{CuO} / \mathrm{UE} / \mathrm{Na}$ on degradation of MO. b Photocatalytic recycling experiments using $\mathrm{CuO} / \mathrm{UE} / \mathrm{Na}$ as the photocatalyst

without any major deactivation. More than $95 \%$ of degradation was achieved after 3 cycles. The reusability studies confirmed that the prepared $\mathrm{CuO}$ nanostructures are having high photocatalytic stability and low photocorrosive effect.

\section{Conclusion}

In summary, the monoclinic structure of $\mathrm{CuO}$ nanostructures with different morphologies were successfully synthesized using presence/absence of low frequency $(42 \mathrm{kHz})$ ultrasound. The results revealed that the morphology of $\mathrm{CuO}$ nanostructures can be controlled by adjusting the parameters like ultrasound, solvent medium and mode of the addition. The as-prepared nanostructures have been systematically investigated by using XRD, TEM, SEM, FTIR and UV-vis spectroscopies. The photocatalytic performance of different $\mathrm{CuO}$ nanostructures for the degradation of $\mathrm{MO}$ was evaluated. The morphology of $\mathrm{CuO}$ nanocatalyst played a key role in determining the catalytic activities. The spherical shaped $\mathrm{CuO}$ nanostructures exhibited a higher catalytic efficiency of MO than the other morphologies. We concluded that the smaller size and high surface area of the spherical nanostructures are the responsible factors for the higher catalytic properties.

Acknowledgments The author gratefully acknowledges the FONDECYT Post-doctoral Project No. 3140178 Government of Chile, Santiago, for the financial assistance.

\section{References}

1. A.S. Edelstein, R.C. Cammaratra, Nanomaterials: Synthesis, Properties and Applications, 2nd edn. (CRC Press, Boca Raton, 1998), p. 616
2. H. Zhong, Z. Bai, B. Zou, J. Phys. Chem. Lett. 3, 3167-3175 (2012)

3. A. Allagui, T. Salameh, H. Alawadhi, J. Electroanal. Chem. 750, 107-113 (2015)

4. J.H. Bang, P.V. Kamat, ACS Nano 3, 1467-1476 (2009)

5. F.G. Banica, Chemical Sensors and Biosensors: Fundamentals and Applications (Wiley, Hoboken, 2012), p. 576

6. F. Zaera, ChemSusChem 6, 1797-1820 (2013)

7. Y. Fan, R. Liu, W. Du, Q. Lu, H. Pang, F. Gao, J. Mater. Chem. 22, 12609-12617 (2012)

8. A.B. Kuzmenko, D. van der Marel, P.J.M. van Bentum, E.A. Tishchenko, C. Presura, A.A. Bush, Phys. Rev. B 63(1-15), 094303 (2001)

9. G. Chen, J.M. Langlois, Y. Guo, W.A. Goddard, Proc. Natl. Acad. Sci. U.S.A. 86, 3447-3451 (1989)

10. D.R. Saha, M. Mukherjee, D. Chakravorty, J. Magn. Magn. Mater. 324, 4073-4077 (2012)

11. M. Muhibbullah, M. Ichimura, Jpn. J. Appl. Phys. 49(1-4), 081102 (2010)

12. X. Liu, D. Wang, Y. Li, Nano Today 7, 448-466 (2012)

13. Y. Li, Q. Liu, W. Shen, Dalton Trans. 40, 5811-5826 (2011)

14. S. Ghosh, M.K. Naskar, RSC Adv. 3, 13728-1 (2013)

15. W. Wang, Q. Zhou, X. Fei, Y. He, P. Zhang, G. Zhang, L. Peng, W. Xie, CrystEngComm 12, 2232-2237 (2010)

16. M. Outokesh, M. Hosseinpour, S.J. Ahmadi, T. Mousavand, S. Sadjadi, W. Soltanian, Ind. Eng. Chem. Res. 50, 3540-3554 (2011)

17. C. Yang, F. Xiao, J. Wang, X. Su, J. Colloid Interface Sci. 435, 34-42 (2014)

18. X.D. Yang, L.L. Jiang, C.J. Maon, H.L. Niu, J.M. Song, S.Y. Zhang, Mater. Lett. 115, 121-124 (2014)

19. K.M. Shrestha, C.M. Sorensen, K.J. Klabunde, J. Phys. Chem. C 114, 14368-14376 (2010)

20. X.Z. Lin, P. Liu, J.M. Yu, G.W. Yang, J. Phys. Chem. C 113, 17543-17547 (2009)

21. S.H. Kima, A. Umar, R. Kumar, A.A. Ibrahima, G. Kumar, Mater. Lett. 156, 138-141 (2015)

22. X. Xu, D. Xiao, K. Dai, Y. Qub, Y. Yinb, H. Chen, Appl. Surf. Sci. 358, 181-187 (2015)

23. L. Hu, N. Gao, S. Liu, S. Wageh, A.A. Al-Ghamdi, A. Alshahrie, X. Fang, Adv. Funct. Mater. 25, 445-454 (2015)

24. C. Lu, C. Liu, R. Chen, X. Fang, K. Xu, D. Meng, J. Mater. Sci.: Mater. Electron. 27, 6947-6954 (2016)

25. H. Liu, N. Gao, M. Liao, X. Fang, Sci. Rep. 5(1-9), 7716 (2015) 
26. M. Villani, A.B. Alabi, N. Coppede, D. Calestani, L. Lazzarini, A. Zappettini, Cryst. Res. Technol. 49, 594-598 (2014)

27. L. Zheng, S. Han, H. Liu, P. Yu, X. Fang, Small 12, 1527-1536 (2016)

28. Q. Zhang, K. Zhang, D. Xu, G. Yang, H. Huang, F. Nie, C. Liu, S. Yang, Prog. Mater Sci. 60, 208-337 (2014)

29. J. Li, F. Sun, K. Gu, T. Wu, W. Zhai, W. Li, S. Huang, Appl. Catal. A 406, 51-58 (2011)

30. J. Liu, J. Jin, Z. Deng, S.Z. Huang, Z.Y. Hu, L. Wang, C. Wang, L.H. Chen, Y. Li, G.V. Tendeloo, B.L. Su, J. Colloid Interface Sci. 384, 1-9 (2012)

31. Y. Wang, D. Wang, B. Yan, Y. Chen, C. Song, J. Mater. Sci.: Mater. Electron. 27, 6918-6924 (2016)

32. S.P. Meshram, P.V. Adhyapak, U.P. Mulik, D.P. Amalnerkar, Chem. Eng. J. 204-206, 158-168 (2012)

33. A.N. Ejhieh, H.Z. Mobarakeh, J. Ind. Eng. Chem. 20, 1421-1431 (2014)

34. A. Sharma, M. Varshney, J. Park, T.K. Ha, K.H. Chae, H.J. Shin, RSC Adv. 5, 21762-21771 (2015)

35. A. Sharma, M. Varshney, T.K. Ha, K.H. Chae, H.J. Shin, Curr. Appl. Phys. 15, 1148-1155 (2015)

36. Y. Chen, X. Tao, Y. Min, F. Zheng, J. Mater. Sci.: Mater. Electron. 24, 1319-1324 (2013)

37. J. Huang, G. Fu, C. Shi, X. Wang, M. Zhai, C. Gu, J. Phys. Chem. Solids 75, 1011-1016 (2014)

38. C. Suryanarayana, M. Grant Norton, X-ray Diffraction: A Practical Approach (Plenum Press, New York, 1998) pp. 213-221

39. S. Ayyappan, J. Philip, B. Raj, Mater. Chem. Phys. 115, 712-717 (2009)

40. X.Y. Chen, H. Cui, P. Liu, G.W. Yang, Appl. Phys. Lett. 90(1-3), 183118 (2007)

41. G. Kliche, Z.V. Popovic, Phys. Rev. B 42, 10060-10066 (1990)

42. L. Debbichi, M.C. Marco de Lucas, J.F. Pierson, P. Kruger, J. Phys. Chem. C 116, 10232-10237 (2012)

43. C. Chen, Y. Zheng, Y. Zhan, X. Lin, Q. Zheng, K. Wei, Cryst. Growth Des. 8, 3549-3554 (2008)

44. C. Yang, F. Xiao, J. Wang, X. Su, Sens. Actuators, B 207, 177-185 (2015)
45. L. Pan, X. Liu, Z. Sun, C.Q. Sun, J. Mater. Chem. A 1, 8299-8326 (2013)

46. S. Sonia, S. Poongodi, P. Suresh Kumar, D. Mangalaraj, N. Ponpandian, C. Viswanathan, Mater. Sci. Semicond. Process. 30, 585-591(2015)

47. T. Pandiyarajan, R.V. Mangalaraja, B. Karthikeyan, P. Sathishkumar, H.D. Mansilla, D. Contreras, Jose Ruiz, Appl. Phys. A 119, 487-495 (2015)

48. V. Ramaswamy, N.B. Jagtap, S. Vijayanand, D.S. Bhange, P.S. Awati, Mater. Res. Bull. 43, 1145-1152 (2008)

49. H. Wang, C. Xie, W. Zhang, S. Cai, Z. Yang, Y. Gui, J. Hazard. Mater. 141, 645-652 (2007)

50. R. Saravanan, V.K. Gupta, V. Narayanan, A. Stephen, J. Mol. Liq. 181, 133-141 (2013)

51. M. Zhu, G. Diao, Catal. Sci. Technol. 2, 82-84 (2012)

52. X. Zhang, Y. Yang, W. Que, Y. Du, RSC Adv. 6, 81607-81613 (2016)

53. S. Dutta, K. Das, K. Chakrabarti, D. Jana, S.K. De, S. De, J. Phys. D Appl. Phys. 49(1-9), 315107 (2016)

54. A.N. Ejhieh, M.K. Shamsabadi, Appl. Cataly A 477, 83-92 (2014)

55. M.M. Hossain, H. Shima, MdA Islam, M. Hasand, M. Lee, RSC Adv. 6, 4170-4182 (2016)

56. R. Kalyani, K. Gurunathan, J. Mater. Sci.: Mater. Electron. (2016). doi:10.1007/s10854-016-5160-7

57. D. Malwal, P. Gopinath, Catal. Sci. Technol. (2016). doi:10.1039/ C6CY00128A

58. W. Wang, L. Wang, H. Shi, Y. Liang, CrystEngComm 14, 5914-5922 (2012)

59. A. Chithambararaj, N.S. Sanjini, S. Velmathi, A. Chandra Bose, Phys. Chem. Chem. Phys. 15, 14761-14769 (2013)

60. C.H. Wu, J.M. Chern, Ind. Eng. Chem. Res. 45, 6450-6457 (2006)

61. C.C. Wang, J.R. Li, X.L. Lv, Y.Q. Zhang, G. Guo, Energy. Environ Sci. 7, 2831-2867 (2014) 